\title{
Primary Fallopian Tube Carcinoma Discovered as an Incidental Finding - A Case Report
}

\section{Mrinalini Singh', Sanjay Kumar Das ${ }^{2}$ and Shilpi Shaukin ${ }^{1}$}

1Department of Pathology, Birat Medical College and Teaching Hospital, Tankisinwari, Morang, Nepal 2Sriram Diagnostic Clinic, Biratnagar, Morang, Nepal

\section{ABSTRACT}

Introduction: Primary malignant tumour of fallopian tube is very rare. The reported incidence of tumour varies from 0.1 to $1.8 \%$ of all gynaecological cancers. There is no specific clinical feature and therefore the disease is often misdiagnosed as ovarian neoplasm or other gynaecological tumours. A preoperative diagnosis even by radiological assay is many times difficult because the features are similar to ovarian neoplasm, tubo-ovarian abscess or hydrosalpinx. We report a case of 45 years old female who presented with multiple episodes of pervaginum bleeding since past one year and was diagnosed as primary fallopian tube carcinoma on histopathology examination.

Keywords: primary malignant tumor; fallopian tube; pervaginum bleeding

Correspondence: Mrinalini Singh, Department of Pathology, Birat Medical College and Teaching Hospital, Tankisinwari, Morang, Nepal. Email: mrinalinisingh1972@gmail.com

DOI: http://dx.doi.org/10.3126/mjsbh.v17i2.20212

Submitted on: 2018-06-09

Accepted on: 2018-06-29 


\section{INTRODUCTION}

The reported incidence of primary fallopian tube carcinoma is 0.41 per 100,000 women. ${ }^{1}$ On an average each year 20-30 new cases are reported. ${ }^{2-4}$ In the early stage the disease may remain asymptomatic. The classical clinical signs and symptoms are watery discharge, vaginal bleeding, and lower abdominal pain or a pelvic mass. But only few patients show all of these symptoms. The most common histologic type is adenocarcinoma.

Many of the times diagnosis of primary fallopian tube carcinoma is missed preoperatively and it is most of the times first appreciated by the pathologist. The better survival rate of the patient depends upon the early diagnosis of the tumour. The aim of this case report is to introduce woman with repeated episodes of irregular menstrual cycles with heavy blood flow in which primary fallopian tube carcinoma was diagnosed.

\section{CASE REPORT}

We present a case of 45 years old female who had repeated episodes of irregular menstrual cycles with heavy blood flow since one year. During this period she consulted gynaecologist and underwent through various laboratory tests to rule out the cause of excessive irregular per vaginal bleeding. The test included complete haemogram, thyroid function test and various other biochemical markers. All the parameters were normal. She also

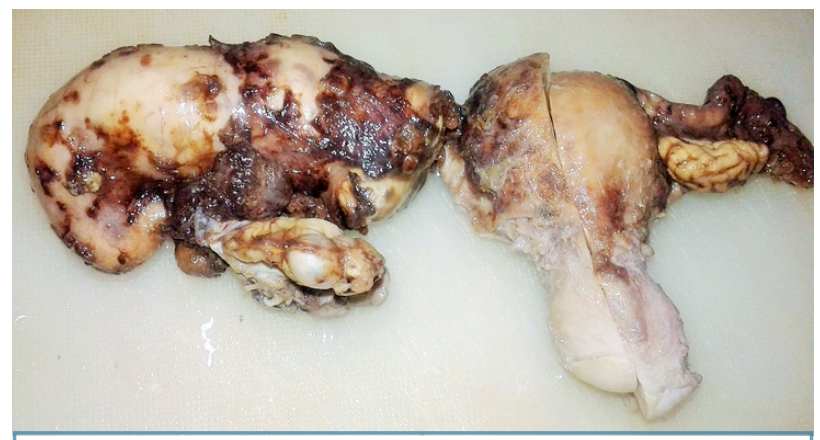

Fig 1. Uterus cervix with normal right adenexa and left ovary (grossly dilated left fallopian tube) underwent ultrasonography done by different radiologist three times during one year period. The radiological findings were suggestive of mild left ovarian enlargement. Since all clinical and laboratory examinations were normal, in view of menorrhagia, total abdominal hysterectomy with bilateral salpingo-oophorectomy was done. On gross examination uterus with cervix measured $6 \mathrm{~cm} \mathrm{x} 4 \mathrm{~cm}$ (Fig 1). Left fallopian tube was dilated and it measured $9 \mathrm{~cm} \times 3 \mathrm{~cm}$. Outer surface was smooth. Cut section was grey white, yellow, solid and filled with focal necrotic material (Fig 2). Left ovary measured $3 \mathrm{~cm} \times 2 \mathrm{~cm}$. Right adnexa was normal. Right fallopian measured $5 \mathrm{~cm}$ in length and $1 \mathrm{~cm}$ in maximum breadth. Right ovary measured $3 \mathrm{~cm} \times 2 \mathrm{~cm}$. Cut section of left ovary revealed normal cystic follicle. Cut section of right ovary was unremarkable. On light microscopic examination the left fallopian tube revealed malignant tumour arising from tubal epithelium and infiltrating full thickness of tubal wall. On high power examination, the individual tumour cells were arranged in glandular and focal papillary pattern along with solid sheets. Cells were enlarged with high N/C ratio. Few atypical mitosis was also seen (Fig 3). Both the ovaries and the right side fallopian tube were free of tumour. Sections examined from cervix and endometrium reveal

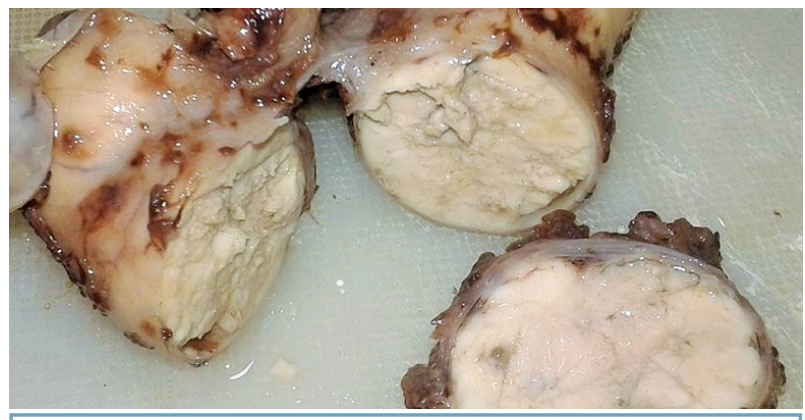

Fig 2. Cut surface of left tube with grey white tumour with focal necrotic area within tubal lumen . 


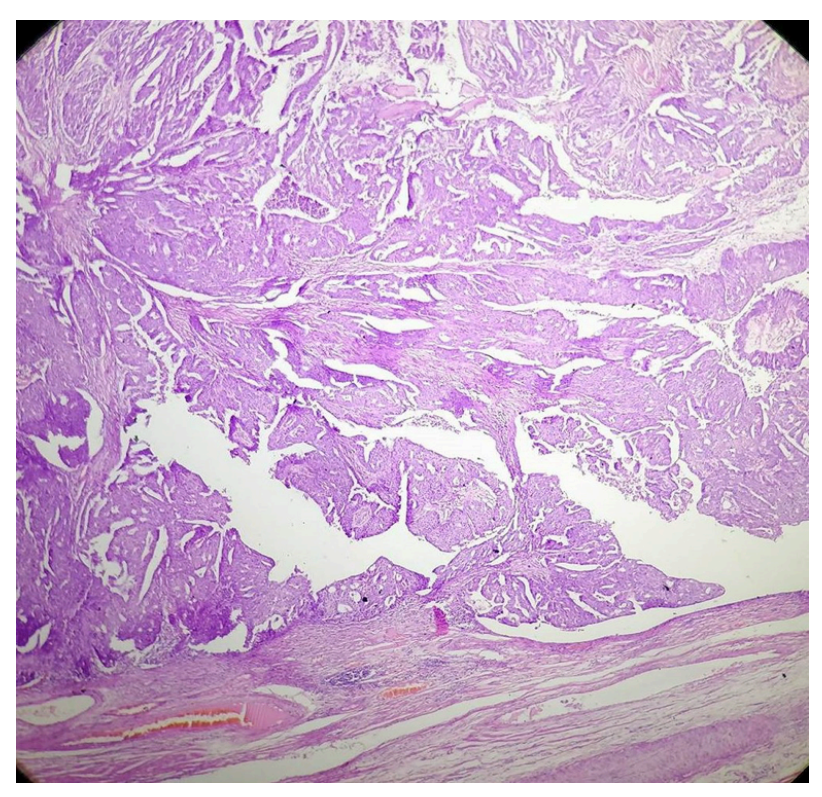

Fig 3. Haematoxylin and Eosin stain $4 x$ showing tumour cells arising from tubal epithelium

features of chronic pelvic inflammatory disease and were free of tumour.

\section{DISCUSSION}

Among all gynaecological malignancies primary fallopian tube carcinoma is the least common type. Since it is uncommon, a definite preoperative diagnosis is rarely made. In their studies AlvaradoCabrero et al. found that a definite preoperative diagnosis was seen in only $4.6 \%$ of the patients. ${ }^{5}$

Various studies have shown that majority of the patients are postmenopausal with the peak incidence between 60 to 64 years. ${ }^{6}$ Other studies also revealed that pregnancy and high parity have been seen to be protective. ${ }^{7}$ However our patient did not show any predisposing risk factors. She was neither postmenopausal nor nullipara. She was only 45 years old and was multigravida with two living child. The classical Latzko's triad of symptoms of fallopian tube carcinoma comprising of watery discharge, vaginal bleeding, and lower abdominal pain or a pelvic mass has been reported only in $15 \%$ of the cases. ${ }^{8}$ Even our patient only presented with menorrhagia. So clinical presentation of this tumour is non specific and varies from patient to patient. The histologic type of our tumour was adenocarcinoma. Stewart et al. did a large series of study and found the most common histologic subtype as adenocarcinoma. ${ }^{1}$

\section{CONCLUSIONS}

The main purpose of this case report is to suggest clinician and radiologist to keep in mind about this rare tumour when observing a gynaecological case. Further new studies suggest that fallopian tube carcinoma is much more frequent then previously observed. Further studies are going on individual with BRCA1 and BRCA2 mutations to identify as a risk factor for primary fallopian tube carcinoma. ${ }^{9}$

To cite this article: Singh M, Das SK, Shaukin S. Primary fallopian tube carcinoma discovered as an incidental finding - A case report. MJSBH. 2018;17(2):64-7.

Conflict of Interest: None declared

\section{REFERENCES}

1. Stewart SL, Wike JM, Foster SL, Michaud F. The incidence of primary fallopian tube cancer in the United States. Gynecologic Oncology. 2007 Dec;107(3):392-7.

DOI: https://doi.org/10.1016/j.ygyno.2007.09.018 PMid:17961642 
2. Gadducci A, Landoni F, Sartori E, Maggino T, Zola P, Gabriele A, et al.Analysis of treatment failures and survival of patients with fallopian tube carcinoma: a cooperation task force (CTF) study. Gynecol Oncol. 2001;81(2):150-9.

DOI: https://doi.org/10.1006/gyno.2001.6134

PMid:11330942

3. Klein M, Rosen AC, Lahousen M, Graf AH, Rainer A. Lymphadenectomy in primary. Cancer Lett. 1999;147(1-2):63-6.

DOI: https://doi.org/10.1016/S0304-3835(99)00273-6

4. Kosary C, Trimble EL. Treatment and survival for women with Fallopian tube carcinoma: a populationbased study. Gynecol Oncol. 2002;86(2):190-1.

DOI: https://doi.org/10.1006/gyno.2002.6743

PMid:12144827

5. Alvarado-Cabrero I, Young RH, Vamvakas EC, Scully RE. Carcinoma of the fallopian tube: a clinicopathological study of 105 cases with observations on staging and prognostic factors. Gynecol Oncol. 1999;72:367-79.

DOI: https://doi.org/10.1006/gyno.1998.5267

PMid:10053109

6. Jeung IC, Lee YS, Lee HN, Park EK. Primary carcinoma of the fallopian tube: report of two cases with literature review. Cancer Res Treat. 2009;41(2):113-6.

DOI: https://doi.org/10.4143/crt.2009.41.2.113

PMid:19707511 PMCid:PMC2731206

7. Riska A, Leminen A. Determinants of incidence of primary fallopian tube carcinoma (PFTC). Methods Mol Biol. 2009;472:387-96.

DOI: https://doi.org/10.1007/978-1-60327-492-0_18ＩMid:19107444

8. Lau H-Y. Primary fallopian tube carcinoma: a clinicopathological analysis and literature review. J Chin Med Assoc. 2013;76(10):583-7.

DOI: https://doi.org/10.1016/j.jcma.2013.06.010 PMid:23890835

9. Piek JM, van Diest PJ, Verheijen RH. Ovarian carcinogenesis: an alternative hypothesis. In Ovarian Cancer. 2008;79-7

DOI: https://doi.org/10.1007/978-0-387-68969-2_7 